\title{
O COTIDIANO DAS FAMILIAS QUE CONVIVEM COM O HIV: UM RELATO DE EXPERIÊNCIA
}

\author{
The Every Day Life of Families that Lives with HIV: \\ An Experience Report \\ El Cotidiano de las Familias que Conviven con el VIH: \\ Un Relato de Experiencia
}

Mariana Vieira

Maria Itayra Coelho de Souza Padilha

\begin{abstract}
Resumo
Trata de um relato da experiência de prática assistencial que teve como objetivo aplicar os princípios da Teoria Humanista de Paterson e Zderad no cuidado às famílias soropositivas para o HIV que convivem com a criança também soropositiva, que frequenta em um Hospital-Dia, para seleção/delineamento dos sujeitos e consultas de enfermagem, em uma Unidade Local de Saúde, ambos em Florianópolis. Foram realizadas nove consultas de enfermagem, três com cada família; no entanto, descrevemos neste artigo a implementação com uma das famílias. Podemos afirmar que a aplicação dos princípios da teoria de Paterson e Zderad proporcionou a confirmação de que a família vem a estar melhor mediante a presença da interação, do diálogo. E nestes momentos de interação, a partir das consultas de enfermagem, detectamos as estratégias, desenvolvidas pelas mesmas, como: apoio familiar, religião, medicamentos, alimentação, lazer, carinho entre outras.
\end{abstract}

Palavras-chave: Família. Criança. HIV. Enfermagem.

\begin{abstract}
This study reports the experience of a care practice. Its objective was to apply the principles of the humanist theory of Paterson and Zderad for care for HIV-positive families who live with an HIV-positive child. The selection and outlining of the subjects took place in Hospital Dia (Every Day Hospital), while the nursing consultancies took place in an Unidade Local de Saúde (Local Health Care Clinic), both in Florianópolis, Santa Catarina, Brazil. Nine nursing consultancies occurred; three with each respective family, and one can affirm that the application of the principles of the theory of Paterson and Zderad provided confirmation that the family improves their well-being given the presence of interaction and of dialogue. It is in these moments of interaction, from nursing consultancies, that we detect the strategies developed by the nursing themselves such as: family support, religion, medication, food, leisure, physical contact, and others.
\end{abstract}

\section{Resumen}

Se trata de un relato de experiencia de práctica asistencial que tuvo como objetivo aplicar los principios de la Teoría Humanista de Paterson y Zderad en el cuidado a las familias suero positivas para el HIV que conviven con el niño también suero positivo, que frecuenta un Hospital Día, para selección/ delineamiento de los sujetos y consultas de enfermería, en una Unidad Local de Salud, ambos en Florianópolis, Santa Catarina, Brasil. Se realizaron nueve consultas de enfermería, tres con cada familia, sin embargo describimos en este artículo la implementación con una de las familias. Podemos afirmar que la aplicación de los principios de la Teoría de Paterson y Zderad nos confirmó que la familia se encuentra mejor mediante la interacción a través del diálogo. Y en estos momentos de interacción, a partir de las consultas de enfermería, detectamos las estrategias, desarrolladas por las mismas, como: apoyo familiar, religión, medicamentos, alimentación, diversión, cariño, entre otras. 


\section{INTRODUÇÃO}

0 Vírus da Imunodeficiência Adquirida (HIV) teve seu aparecimento nos anos de 1980 e esteve ligado a diversos significados, tais como desordem social, catástrofes e castigos, condenando as pessoas à morte iminente. 0 conhecimento sobre a doença desde o início de seu surgimento, que se mantém até 0 momento, é o de associar que a epidemia do HIV/AIDS ocorre pelos comportamentos julgados como pecaminosos, a exemplo do uso de drogas, homossexualismo e prostituição".

É importante reforçar que, no decorrer dos anos, o padrão de transmissão do HIV no Brasil vem mudando e atualmente não está mais associado aos grupos de risco. Uma prova deste fato, de acordo com os indicadores epidemiológicos, está no aumento de números de casos de HIV/AIDS relacionados à exposição heterossexual, e, com isto, uma proporção também cada vez maior de mulheres são atingidas².

Em decorrência do aumento da vulnerabilidade feminina, aumentando também a vulnerabilidade de crianças em relação à epidemia, o sistema familiar torna-se 0 alvo principal para 0 desenvolvimento do HIV, determinando sentimentos de ameaças e discriminação perante a sociedade. Tal fato ocorre porque as crianças são vistas socialmente como as vítimas do HIV, pois não praticam comportamentos de risco, o que transfere para os pais a culpa atribuída ao diagnóstico de HIV, o que pode provocar graves rupturas na unidade familiar ${ }^{3}$.

A família é identificada como uma indispensável unidade cuidadora da criança soropositiva para o HIV, que necessita também de cuidado. Para assistir à família como uma unidade de cuidado, os enfermeiros devem considerar não só a saúde individual dos seus membros, mas também a saúde grupal, a qual se nomeia como saúde familiar'.

A família neste estudo é compreendida como um grupo de pessoas que vivem juntas e compartilham a mesma realidade, geralmente comungando das mesmas idéias e sentimentos, cuidando uns dos outros, dividindo normalmente um mesmo espaço e tendo atividades em comum. Assim, pensamos que a família soropositiva para o HIV, que convive com a criança também soropositiva, é uma unidade de cuidado e fonte de ajuda para esta criança contribuindo para o seu bem-estar e o seu estar melhor.

A opção em desenvolver uma prática assistencial junto às famílias soropositivas para o HIV, especialmente mães que convivem com a crianças também soropositivas, funda-se na compreensão de que elas necessitam de ajuda. Acreditamos que para ajudá-las é necessário conhecer suas estratégias desenvolvidas de famílias soropositivas para o HIV para conviver com criança também HIV positiva. Pensamos que isto as ajudaria a amenizar seu sofrimento, angústia e medo, decorrentes da discriminação e do preconceito advindos da construção social e cultural do HIV.

A empatia e a comunicação são formas de interação com a família, configurando-se em instrumentos importantes para que o processo de educação em saúde aconteça, sendo necessário o envolvimento existencial da enfermeira no cuidado prestado, o que será manifestado na presença ativa desta profissional, no tempo e espaço vivido pelo indivíduo.
Nesse sentido, referenciais como de Paterson e Zderad têm ajudado a Enfermagem a cuidar de maneira diferenciada, com uma visão ampla e sistêmica da sociedade, das famílias/ crianças e da instituição. Através de abordagens tais é que a enfermeira poderá agir e, assim, fornecer um estar melhor à família e à criança soropositivas para o HIV 5 .

Portanto, para que se possa ter uma abordagem compreensiva da família e da criança soropositivas para o HIV, enquanto enfermeira e cuidadora na área da saúde, é necessário compartilhar com a família e identificar no seu cotidiano, a sua percepção e seu entendimento próprio de família, da situação do HIV, abordando temas como: o que está sentindo e como está se organizando diante desta vivência; e identificar as necessidades de ajuda, como pessoa e como parceiro no cuidado, na perspectiva de integrá-lo à dinâmica do processo de cuidar de forma humanizada e segura. Em função da problemática anteriormente levantada, pretendemos buscar respostas, para o seguinte questionamento: "Quais são as estratégias que as famílias desenvolvem para conviver com o diagnóstico de HIV?".

Ao realizar este trabalho, procuramos conhecer as estratégias desenvolvidas pelas famílias para conviver com 0 HIV, assim como com a criança soropositiva para o HIV, para propor uma assistência de enfermagem humanizada, considerando o cotidiano das famílias permeado por suas culturas, valores, crenças. Para uma melhor compreensão deste processo e desenvolvimento desta prática, utilizamos os conceitos da Teoria Humanista de Paterson e Zderad, por entender que 0 cuidado de enfermagem humanizado é essencial para a promoção e manutenção satisfatória da saúde ${ }^{6}$. Os conceitos utilizados a partir destes referenciais foram: ser humano, enfermagem; cuidado humanizado; saúde/doença e ambiente.

Neste sentido, esta prática assistencial teve como objetivo geral aplicar os princípios da Teoria Humanista de Paterson e Zderad no cuidado às famílias que convivem com a criança soropositiva para o HIV e, como objetivos específicos, conhecer o cotidiano das famílias para conviver com o diagnóstico de HIV, assim como com a criança soropositiva, e planejar, executar e avaliar o cuidado prestado às famílias HIV soropositivas fundamentado na Teoria Humanista de Paterson e Zderad.

\section{METODOLOGIA}

A prática assistencial ocorreu em dois contextos. Inicialmente em um Hospital-Dia, o qual foi utilizado para seleção e delineamento dos sujeitos, e, depois, em uma Unidade Local de Saúde para a realização das consultas de enfermagem, pois este local propiciou um maior vínculo e a interação com as famílias. Os dois locais estão em um mesmo bairro do Município de Florianópolis - SC. 0 Hospital-Dia atende em média 35 crianças por semana provenientes de várias regiões do Estado. Elas são atendidas por equipe multiprofissional em consultas agendadas a cada três meses ou conforme a necessidade. $\mathrm{Na}$ Unidade Local de Saúde há três equipes de Programa de Saúde da Família atuantes (médicos, enfermeiros, técnicos em enfermagem, odontólogos). Esta unidade funciona diariamente e atende à comunidade do bairro. 
Adotamos como sujeitos desta prática assistencial três famílias com crianças soropositivas para o HIV, cujo foco central para a aplicação dos princípios propostos por Paterson e Zderad foi a mãe biológica. Os critérios de inclusão foram: mães biológicas soropositivas para o HIV que convivem com a criança HIV; que realizam o acompanhamento da criança no Ambulatório do Hospital-Dia e que permitiram sua participação no estudo. A prática assistencial aconteceu durante o período de abril a novembro de 2006, por meio de encontros para a realização da consulta de enfermagem. 0 caminho metodológico para a seleção das participantes da experiência foi organizado nos seguintes momentos:

(a) Primeiro Momento: apresentamos o interesse pela execução da prática assistencial à equipe de saúde do HospitalDia e, a partir da permissão, enviamos o projeto para avaliação da Comissão de Ética em Pesquisa do Hospital em Estudo, 0 qual foi aprovado segundo parecer consubstanciado de número 012/2006 e registro no CEP de número 015/2006.

(b) Segundo Momento: caracterizou-se pelo período de delineamento/seleção dos sujeitos para a prática assistencial. A seleção das famílias ocorreu inicialmente a partir das investigações sobre os prontuários em ordem alfabética das crianças soropositivas para o HIV. Esta busca mostrou-se ineficiente e a completamos realizando pré-entrevistas com as acompanhantes familiares das crianças soropositivas para o HIV (mãe adotiva, avó, tias), que compareceram ao HospitalDia. Nesta busca selecionamos as mães biológicas HIV soropositivas, que convivem com a criança também HIV e que concordaram em participar do estudo. Para elas foi realizada a leitura do Termo de Consentimento Livre e Esclarecido, a fim de formalizar o aceite da proposta e garantir a observação dos princípios éticos, de acordo com a Resolução 196/96 do Conselho Nacional da Saúde?.

(c) Terceiro Momento: com os sujeitos já selecionados foram marcados três encontros individuais com as três famílias, sendo realizada a consulta de enfermagem com a aplicação dos Princípios da Teoria Humanista de Paterson e Zderad, no cuidado às famílias soropositivas para o HIV que convivem com a criança também soropositiva, totalizando, assim, nove encontros.

\section{IMPLEMENTAÇÃO DA EXPERIÊNCIA DA PRÁTICA ASSISTENCIAL}

Dando continuidade ao caminho metodológico, descrevemos a seguir a Implementação desta Prática Assistencial, a partir de três encontros realizados com apenas uma das famílias/mães que participaram da prática assistencial. A opção em descrever uma família apenas ocorreu de forma a exemplificar o modo como a experiência foi realizada durante a disciplina de Projetos Assistenciais, do Curso de Mestrado em Enfermagem da Universidade Federal de Santa Catarina.

Descrição da experiência de prática assistencial:

E.A.F., 40 anos, sexo feminino, natural e procedente de Agrolândia - SC e residente em Florianópolis - SC, primeiro grau incompleto (até quarta série), do lar, evangélica, casada, HIV há 6 anos, esposo também HIV positivo há 6 anos, por contaminação heterossexual. Têm 6 filhos, sendo os 3 mais velhos do primeiro casamento, 1 do segundo casamento e as outras 2 filhas do casamento atual; destas somente T.A.F, 8 anos, é HIV soropositiva, o que foi descober to quando estava com 2 anos, e a M.E.F, 4 anos, que tornou-se soronegativa em virtude da realização do tratamento com anti-retroviral durante o pré-natal.

0 Primeiro Encontro para realização da Consulta de Enfermagem se deu no dia 16/10/2006, na ULS, e teve como objetivo conhecer a família/mãe HIV soropositiva de modo intuitivo. Para este primeiro encontro, procuramos "entrar" na relação com a família HIV soropositiva sem preconceitos, expectativas, rótulos, julgamentos.

Inicialmente foi realizada com a mãe, sujeito da prática, uma técnica chamada "caracol" para sensibilização e, então, propiciar o estabelecimento de uma relação de interação, vínculo com a família/mãe. Durante esta técnica, E.A.F. escreveu, em um caracol desenhado numa folha de papel, os seus sentimentos naquele momento: "expectativa, certa curiosidade de como seria aquela tarde junto comigo, pessoa esta a quem não tem intimidade". No decorrer da Consulta de Enfermagem, E.A.F. conta como foi que descobriu ter o HIV e que significado teve para ela, a partir do seguinte relato:

Descobri há seis anos, quando minha filha estava com 2 aninhos. Fui fazer o exame preventivo de rotina, lá no posto de saúde de Capoeiras e lá deu alterado ... estava com câncer... fiquei muito mal. (...) Daí fui encaminhada para um hospital, fiz vários exames, até o de Aids. É parece que tô vendo hoje quando a médica disse $o$ resultado ... Meus Deus! Acho que foi assim uma facada no peito, chorei tanto ... (neste momento os olhos de E.A.F. encontravam-se rasantes de lágrimas) ... Me apavorei, me desesperei. (...) Meu Deus! Agora tô morta! Achava que tava morta, porque com câncer, HIV, e como é que vou cuidar de meus filhos.

0 conhecimento do diagnóstico gera diversos sentimentos na vida das pessoas: o medo do preconceito e dos julgamentos que a doença pode gerar, o receio da rejeição da família, dentre outras. 0 enfrentamento da doença e a incorporação da mesma ao processo de viver são questões que normalmente geram ansiedade e sofrimento, principalmente nas pessoas ao descobrirem sua soropositividade ${ }^{8}$. As reações diante do diagnóstico são fortemente influenciadas pelas crenças e valores cultivadas pelo indivíduo, assim como pelo grupo social no qual o mesmo está inserido. 0 relato abaixo exemplifica este aspecto:

Meus filhos e eu no início ficamos revoltados com o meu marido, que me contaminou. (...) No início, eu me revoltei contra ele. Como que ele pode fazer isso? E gritava: 'tu condenasse a gente'.

0 fato da contaminação ter ocorrido numa relação conjugal gera sentimento de culpa, em que os culpados são reconhecidos como aqueles que procuraram a AIDS e as vítimas são aquelas acometidas pela infecção através de comportamentos aceitos socialmente 9 . Neste sentido, acreditamos que as mulheres acabam assumindo o papel de vítimas diante da doença e os homens assumem o de culpados, por terem contraído o vírus fora da relação conjugal e o terem transmitido a companheira. 
Este Primeiro Encontro, através da consulta de enfermagem, caracterizou-se pelo diálogo sobre a vida, o cotidiano de E.A.F., de sua família, assim como sobre o convívio com o HIV. Porém, de maneira geral, o Encontro ocorreu sem a intenção de intervir diante dos problemas apresentados. 0 conversar, dialogar com a família de maneira intuitiva propicia, além do estabelecimento do elo de confiança e do vínculo, o bem-estar e estar melhor da família também, pois, segundo Paterson e Zderad, o encontro permeado de diálogo e interação favorece a família estar melhor na presença do outro.

Ao final deste Encontro foi realizada uma avaliação informal, a partir do relato da família sobre como se deu o momento. E com o consentimento favorável da família para continuar a sua participação na prática, agendamos então um próximo Encontro, para a realização da segunda consulta de enfermagem.

0 Segundo Encontro aconteceu no dia 19/10/2006 na Unidade Local de Saúde, no período vespertino. Caracterizouse pela consulta de enfermagem com roteiro de entrevista que aborda questões acerca das estratégias desenvolvidas pelas famílias para conviver com o HIV, de modo científico. A partir desta consulta de enfermagem foram se delineando os aspectos importantes do cotidiano, que permitiram uma maior compreensão sobre as estratégias utilizadas pela família/mãe no convívio com o HIV. Dentre elas optamos por enfocar o seguinte aspecto: as estratégias para conviver com - HIV após o diagnóstico (apoio família, tratamento medicamentoso, religião, entre outras).

Inicialmente, realizamos uma técnica de sensibilização, durante a qual foi desenhado pela família em um papel como seria sua "vida sem o HIV" e, em outro, como é sua "vida com o HIV". No primeiro papel, E.A.F. desenhou vários bonecos separados e um deles com lágrimas no rosto, que, segundo a participante da prática, representava ela mesma, e, no segundo papel, vários bonecos unidos, sorrindo. Ao final da técnica, E.A.F., relatou:

Com o HIV meus filhos começaram a ficar mais agarrados comigo, mais carinhosos .... Sabe que foi bom? Às vezes são males que vem pra bem. Passei a ser mais amada, coisa que antes eu não era. Porque antes, apesar de tanto filho, eu vivia sozinha, não havia amor. E hoje posso gritar que o amor é tudo. Não há mal que resista quando existe $o$ amor, o apoio, a força da família.

Dentre os aspectos significativos buscados durante esta consulta de enfermagem, ou seja, as estratégias para conviver com o HIV após o diagnóstico, E.A.F. destacou, em relação ao apoio familiar, a importância do mesmo, principalmente dos seus filhos e de sua mãe, no processo de convivio com a doença:

A familia, filhos, irmãos, mãe me deram todo apoio. Pensei que eles iam se afastar de mim, mas não. Sabe que, ao contrário, se aproximaram mais. (...) Com o apoio da família, vi que o HIV não era o fim. Resolvi erguer a cabeça, lutar, ter Deus no coração.

Este depoimento demonstra a estruturação da família/mãe diante da situação do HIV. Há famílias que se estruturam e outras que se desestruturam em relação ao descobrimento do
HIV. 0 que de fato vai direcionar o comportamento da família é a sua cultura, sua crença, assim como o contexto em que a mesma está inserida, levando à discriminação do indivíduo e exclusão do grupo familiar, ou buscando formas para seu enfrentamento e sua superação, tentando reestruturar-se perante a realidade que a doença traz ${ }^{10,11}$. Além do apoio familiar, há também a influência da religião como estratégia da família para conviver com o HIV, representada a partir da seguinte fala:

(...) Eu e a minha mãe, depois de termos recebido a notícia de que eu tenho HIV, saímos abraçadas chorando e entramos numa igreja. Me ajoelhei, chorava muito. $E$ lá ouvi uma palavra de Deus que foi muito boa sabe ... Dali em diante, me apeguei muito a Deus.

Verificamos a forte influência da religião e da família como recursos e estratégias para conviver com o HIV, sobrepondo-se inclusive ao tratamento biomédico. Fatores como religião, crença, cultura e educação influenciam significativamente na decisão por determinados recursos de saúde ${ }^{10}$. Há ainda a importância da ajuda biomédica, com os tratamentos medicamentosos utilizados pela família como recursos à saúde. Estes recursos podem ser exemplificados pela fala apresentada a seguir:

No início passava uns dias sem tomar os remédios. Não aceitava o que estava acontecendo comigo, negava. Mas vi que tava ficando pior: magra, feia, fraca. Daí vi que o remédio era necessário também. (...) 0 médico que me passou os remédios também disse que as pessoas que se cuidam, que fazem o tratamento, podem morrer da velhice, sabe, e não do HIV. Daír resolvi tomar os remédios e agora tô melhor.

A respeito da longevidade dos indivíduos soropositivos para o HIV, o HIV/AIDS está se tornando uma doença crônica, pela possibilidade de longevidade e de qualidade de vida que os indivíduos infectados têm conquistado nos últimos anos ${ }^{12}$. Ainda em relação ao tratamento médico, entre os membros da família, E.A.F. relata:

Meu marido diz que não precisa destas coisas. Diz que não tem nada. Daí não faz tratamento. Eu respeito, né? (...) Graças a Deus, ele não tem ficado doente, está muito bem.

As mulheres aceitam melhor a doença, procuram conservar sua saúde, buscando a biomedicina e outras estratégias do cotidiano para si e seus familiares ${ }^{9}$. Observamos que o objetivo da mulher passa a ser o de viver o maior tempo possível e o desejo de se manter presente para cuidar do companheiro e/ ou filhos. Estas finalidades tornam-se seus principais incentivos.

Outro assunto que permeou o desenvolvimento da consulta de enfermagem foi a prevenção. E, apesar do conhecimento da família sobre a importância da mesma como recurso/estratégia de cuidado no convívio com o HIV, muito ainda há para ser conquistado. Este fato pode ser elucidado a partir da seguinte fala:

Olha não vou mentir. De vez em quando, faço relação sem camisinha. A médica me disse pra não fazer. Daí, eu falo pro meu marido que não é porque nós dois 
temos HIV, que não precisa mais usar a camisinha. Daí, ele acha ruim, fica 'brabo'.

0 homem é mais resistente ao uso do preservativo, independente de sua condição de soropositivo ou não. Apesar de todas as conquistas das mulheres nas últimas décadas, na hora do amor e sexo, é o homem que domina a relação ${ }^{13}$. As mudanças do comportamento sexual, com adoção da prática de sexo seguro, juntamente com a utilização da terapia antiretroviral, está relacionada à redução de riscos à saúde, contribuindo para uma melhor qualidade de vida e sobrevida em pacientes com HIV. No entanto, esta é talvez uma das maiores dificuldades do profissional de saúde, pois se trata de uma situação que ultrapassa os limites da epidemia do HIV/AIDS, uma situação fundada em valores sociais e psicologicamente estabelecidos, que podem se modificar muito lentamente.

0 Terceiro Encontro ocorreu no dia 24/10/2006 na Unidade Local de Saúde, também no período da tarde, por ser o melhor horário para E.A.F. Durante o período da manhã, ela sempre vai à igreja e tem os afazeres da casa, entre outras atividades. Neste encontro procuramos articular as duas fases anteriores, os modos intuitivo e científico, e assim dar continuidade à consulta de enfermagem centrada nas estratégias desenvolvidas pela família para conviver com a criança soropositiva para o HIV.

Como no segundo encontro anterior, a partir da consulta de enfermagem foram se delineando os aspectos importantes do cotidiano da família no convívio com a criança HIV soropositiva. Dentre eles, optamos por enfocar as seguintes: 0 descobrimento do HIV na criança e o significado do diagnóstico para a família; e as estratégias desenvolvidas pela família para conviver com a criança HIV soropositiva.

\section{O descobrimento do HIV na criança e o significado do diagnóstico para a família:}

Neste terceiro encontro, E.A.F. apresenta-se mais aberta para conversar sobre o convívio do HIV na criança, como lida com tal situação, fato que favoreceu a interação e o vínculo construídos desde o primeiro encontro. Neste sentido, apontamos a relevância do Referencial de Paterson e Zderad, o qual enfatiza a importância do encontro, de estar presente e do diálogo para o estabelecimento da confiança. Assim, a família exacerbará seus sentimentos diante do convivio com o HIV, favorecendo seu bem-estar e o estar melhor. E.A.F. inicia o encontro contando como foi o descobrimento do HIV na criança e seus significados. A fala seguinte registra estes aspectos:

Quando foi diagnosticado o HIV em mim, a médica pediu para que todos os meus filhos fizessem o teste pra ver se também tinham o HIV. E daí, foi feito né, do filho mais velho ao mais novo. Daí, só restava fazer na minha filha ... Aí, Meu Deus, era o que eu não queria, mas aconteceu! (...) Hoje preciso arranjar um jeito de contar pra ela. ... Tá difícil, não tenho coragem. Tenho medo de ela se revoltar contra mim. (...) 'Tadinha', ela não precisava tá passando por isso. A culpada fui eu.

Tal fato decorre das crianças serem vistas como as vítimas do HIV, pois não praticam comportamentos de risco, o que transfere para os pais a culpa atribuída ao diagnóstico de HIV, podendo provocar graves rupturas na unidade familiar ${ }^{3}$.

As estratégias desenvolvidas no cotidiano pela família para conviver com a criança HIV soropositiva:

Quanto às estratégias desenvolvidas pela família/mãe para conviver com a criança HIV soropositiva, foram ressaltados vários aspectos, tais como: tratamento medicamentoso, hábitos de vida, alimentação, educação e lazer, dentre outros. Em todo momento, a família deixou claro que a sua estratégia no convívio com a criança soropositiva para o HIV é a importância de não superprotegê-la, cuidando dela da mesma maneira que os irmãos são cuidados. 0 relato apresentado a seguir exemplifica estes pontos:

(...) E ela foi a escolhida pelo HIV. ... Mas, trato ela normal, como os outros filhos e não fico protegendo não. Não quero que ela se sinta a 'coitadinha' e nem que os outros olhem pra ela com pena ... . Ninguém passa a mão na cabeça de ninguém.

Há famílias que agem e reagem das mais diversas maneiras, desde momentos de instabilidade até os de uma superproteção, impedindo que a criança desenvolva suas potencialidades e também aprenda a reconhecer limites ${ }^{11}$. Assim, a fim de evitar estas atitudes, consideramos importante a presença da Enfermagem para ajudar a conviver com os sentimentos de negação, incerteza, culpa, desconfiança, discriminação, entre outros, exacerbados pelos familiares da criança soropositiva para o HIV. Alguns familiares apresentam dificuldades no enfrentamento da situação, podendo interferir mais negativamente no cotidiano das crianças.

Durante esta consulta de enfermagem, E.A.F. foi relatando o seu dia-a-dia junto com a criança HIV soropositiva. E a partir destes relatos foi possível conhecer algumas das estratégias/ recursos à saúde, como tratamento medicamentoso, alimentação, educação e lazer, todas(os) utilizadas(os) pela família para conviver com a criança HIV soropositiva. Dentre elas(es), destacam-se os relatos que demonstram que as estratégias de convívio desenvolvidas pelas famílias junto a essas crianças não se limitam ao uso de medicações, mas também aos hábitos de vida diários, tais como a alimentação, 0 lazer, a educação e o amor. E é neste cenário que surge a manifestação da família, em especial do comportamento feminino (da mãe), através do cuidado de si e do outro, no caso a criança, em busca de uma melhor qualidade de vida. A seguinte fala exemplifica estes pontos:

Sou eu quem dou pra ela os remédios. Me preocupo também, ... de minha filha estar bem alimentada. Faço feijão, vitaminas ... de estar com saúde e de dar muito carinho, porque isso é tudo. Mais que dar só os medicamentos.

Tal relato demonstra a importância da família, em especial da mãe, no cuidado à criança HIV soropositiva. Neste contexto, entendemos a família como uma indispensável unidade cuidadora da criança soropositiva para o HIV, a qual desenvolve estratégias para conviver com a criança com este diagnóstico e ressaltamos que estas famílias necessitam, por sua vez, também 
serem cuidadas ${ }^{4}$. A família que convive com a criança HIV soropositiva necessita de um olhar diferenciado, e não desigual. A criança acometida pelo HIV continua sendo a mesma, um ser humano único e singular, com a diferença de que, circunstancialmente, entrou em contato com o HIV. Há de se salientar ainda algumas adaptações realizadas pela família para conviver com o HIV, bem como com a criança HIV soropositiva. Dentre elas, destacam-se:

Comecei a ler mais sobre ele [HIV]. Passei a me interessar mais. Meus filhos também, (...) sabe, a querer entender melhor o que é HIV e a AIDS, porque pra mim tudo era a mesma coisa. (...) No colégio que a minha filha estuda a diretora sabe, porque eu tinha que mandar, né, os medicamentos pra ela tomar no horário certo. Mas agora já adaptei o horário pra não precisar levar os remédios pro colégio. (...) Comecei a falar (...) muito mais com os outros. É bom demais, colocar pra fora os medos, as dúvidas, ter alguém pra gente falar e pra nos ouvir nós, né?

0 HIV provoca alterações na vida das pessoas. Não somente na estrutura e funcionamento do organismo, mas também nas condições e na qualidade de vida. Isto alerta para a necessidade de um cuidado maior consigo mesmo, adotando ou intensificando práticas de cuidado à saúde ${ }^{14}$. Neste sentido, acreditamos que a família deve buscar se adaptar e se reorganizar para enfrentar a experiência de viver e (con)viver com o HIV.

Ressaltamos a importância da atuação da Enfermagem, sistematizando, desenvolvendo e avaliando o processo de cuidar da família e da criança, envolvidas num só contexto. Para tanto, cremos que o profissional de enfermagem deve compreender a dinâmica familiar alterada em função do HIV para, a partir de então, propor um cuidar humanizado, sem julgar, sem procurar culpados ou inocentes. Ao cuidar da pessoa HIV soropositiva, é necessário respeitá-la e vê-la na sua individualidade, sendo imprescindível o conhecimento acerca da ética e da moral, princípios que propiciam uma nova razão, instrumental, emocional e espiritual ${ }^{12}$.

\section{CONSIDERAÇÕES FINAIS SOBRE A EXPERIÊNCIA DE PRÁTICA ASSISTENCIAL}

A avaliação da prática assistencial junto às famílias/mães que convivem com crianças, ambas soropositivas para o HIV, ocorreu no decorrer das consultas de enfermagem. Durante as mesmas, a aplicação dos princípios da Teoria de Paterson eZderad foi avaliada no processo de cuidar dessa família/mãe e criança.

\section{Referências}

1. Souza AS. A convivência da família com o sujeito portador do vírus HIV/AIDS. 2000. 280 f. [dissertação de mestrado]. Florianópolis (SC): Programa de Pós-Graduação em Enfermagem / UFSC; 2000.

2. Ministério da Saúde(BR). Controle das Doenças Sexualmente Transmissíveis- DSTs. Secretaria de Vigilância em Saúde. Programa Nacional de DST e AIDS. Brasília (DF); 2006.
A Teoria Humanista de Paterson eZderad mostrou-se adequada para conhecer o cotidiano, as estratégias desenvolvidas pelas famílias e a influência delas no convivio com o HIV, assim como com a criança soropositiva para o HIV. A aplicação do processo de enfermagem, a partir de Paterson e Zderad, proporcionou a confirmação de que a família vem a estar melhor mediante a presença da interação e do diálogo e vínculo com o outro.

Nestes momentos de interação junto à família, a partir das consultas de enfermagem, detectamos as estratégias desenvolvidas, adaptadas pelas mesmas para conviver com 0 HIV. Dentre elas destacaram-se hábitos do cotidiano, tais como alimentação, educação, lazer, prática sexual sem o uso de preservativo, entre outras. Em relação às estratégias até então detectadas como inadequadas, como a falta de uso de preservativo, procurou-se esclarecer sobre a importância do seu uso, os riscos e as possíveis complicações advindas desta prática.

Ao abordar as questões relacionadas à vivência de ter HIV/ AIDS, conseguimos ampliar a discussão em direção à saúde integral, às dimensões subjetivas, emocionais e relacionais e às do cotidiano, incluindo a sexualidade e as relações amorosas. Este tipo de experiência nos permitiu ampliar a compreensão do trabalho da enfermagem e, também, de suas limitações, condicionamentos culturais, morais, sociais e pensá-los criticamente, a fim de evitar atitudes de discriminação, preconceito, no cuidado prestado à família, estabelecendo assim uma relação ética.

Compreender as estratégias do cotidiano desenvolvidas pelo indivíduo soropositivo para o HIV foi um desafio permanente, que exigiu compromisso afetivo e uma relação de permanente diálogo, o que implicou em "saber escutar"8. Neste sentido, Paterson e Zderad enfatizam que o encontro, o diálogo e a presença com o outro são princípios fundamentais em sua teoria. Os encontros tiveram como atitude diferencial a preocupação em favorecer um espaço aberto para a família falar de si e da criança, no convívio com o HIV.

Este estudo não se propôs a mudar os comportamentos, as estratégias desenvolvidas pela família para conviver com o HIV e com a criança também HIV soropositiva, mas sim, buscou despertar nos participantes uma reflexão sobre a experiência de viver com HIV, suas estratégias de cuidado, assim como refletir sobre os pontos de conflito no que diz respeito à temática do HIV.

Intervir nestas questões, enquanto profissionais de saúde, nos remete a desafios de várias ordens. A superação destes desafios é algo a ser conquistado lentamente, com empenho, empatia e aprofundamento teórico, escutando o que o outro tem a nos dizer e, sobretudo, respeitando suas atitudes e decisões.

3. Silva KM, Silva M. Cuidando e promovendo o bem estar e o estar melhor de crianças/famílias portadoras de HIV/AIDS. Uma abordagem existencialfenomenológica-humanista, 2002. 89 f [monografia de graduação]. Florianópolis (SC) Curso de Graduação em Enfermagem / UFSC; 2002.

4. Elsen I. Desafios de enfermagem:marcos para a prática de enfermagem com famílias. Florianópolis(SC): Ed. UFSC; 1994. Série enfermagem.

5. George JB. Teorias de enfermagem: os fundamentos da prática profissional. Porto Alegre(RS): Artes Médicas; 1993. 
6. Paterson J, Zderad L. Enfermería humanística. México: Limusa; 1979.

7. Ministério da Saúde (BR). Conselho Nacional de Saúde. Resolução nÚ196 de 10 outubro de 1996 Diretrizes e normas regulamentadoras de pesquisas envolvendo seres humanos. Brasília(DF); 1996. 24 p.

8. Domingues RC. Notas sobre os aspectos psicossociais do diagnóstico anti-HIV: uma reflexão sobre as possibilidades de prevenção e assistência a partir da prática do aconselhamento. In: Centro de Testagem e Aconselhamento-CTA: integrando prevenção e assistência. Brasília(DF): Ministério da Saúde; 2004.

9. Knauth Dr. Morte masculina: homens portadores do vírus da Aids sob a perspectiva feminina. In: Duarte LFD, Leal OF. Doença, sofrimento, perturbação: perspectivas etnográficas. Rio de Janeiro(RJ): FIOCRUZ, 1998.

10. Lage E. Perspectiva no estudo da representação social da AIDS. Esc Anna Nery Rev . Enferm. 2003; dez 12(3): 347-55.

11. Pedro ENR. Vivências e convivências de crianças portadoras de HIV/AIDS e seus familiares: implicações educacionais. Rev Paulista Enferm 2003 mar; 22(1): 62-71.

12. Maliska ICA. 0 Itinerário terapêutico dos indivíduos portadores do HIV/AIDS., 2005. $150 \mathrm{f}$ [dissertação de mestrado]. Florianópolis(SC): Programa de Pós-Graduação em Enfermagem / UFSC; 2005
13. Achkar S. Aconselhamento e prevenção: alcances de limites. In: Ministério da Saúde (BR) Centro de Testagem e Aconselhamento-CTA: integrando prevenção e assistência. Brasília(DF):, 2004.

14. Marques SC, Francisco MTR, Clos AC. A identificação da representação social da AIDS a partir da técnica de análise de correspondências múltiplas. Rev Enferm UERJ; 2003 dez : 11(3): 328-36.

15. Aves IC, Padilha MICS, Mancia J R. A equipe de enfermagem e 0 exercício do cuidado a clientes portadores de HIV/AIDS. Rev Enferm UERJ 2004:133 - 39.

\section{Sobre as Autoras}

\section{Mariana Vieira}

Enfermeira Mestranda do Programa de Pós-Graduação da Universidade Federal de Santa Catarina. Especialista em Enfermagem do Trabalho; Membro do Grupo de Estudos da Historia e Conhecimento em Enfermagem - GEHCE.

\section{Maria Itayra Coelho de Souza Padilha}

Doutora em Enfermagem Orientadora e Professora Associada do Depto de Enfermagem da Universidade Federal de Santa Catarina. Vice Líder do GEHCE. Pesquisadora do CNPq. 